\title{
Sclerosing lipogranuloma of the penis: a narrative review of complications and treatment
}

\author{
Boyke Soebhali $^{1}$, João Felicio ${ }^{2} \wedge$, Pedro Oliveira ${ }^{2}$, Francisco E. Martins ${ }^{2} \wedge$ \\ ${ }^{1}$ Medical Faculty, Mulawarman University, Abdul Wahab Sjahranie Hospital, Samarinda, Indonesia; ${ }^{2}$ Department of Urology, University of Lisbon, \\ School of Medicine, Santa Maria Teaching Hospital, Lisbon, Portugal \\ Contributions: (I) Conception and design: B Soebhali, FE Martins; (II) Administrative support: B Soebhali, FE Martins; (III) Provision of study \\ materials or patients: B Soebhali, FE Martins; (IV) Collection and assembly of data: All authors; (V) Data analysis and interpretation: All authors; (VI) \\ Manuscript writing: All/Both authors; (VII) Final approval of manuscript: All authors. \\ Correspondence to: Francisco E. Martins. Department of Urology, University of Lisbon, School of Medicine, Santa Maria Teaching Hospital, Lisbon, \\ Portugal. Email: faemartins@gmail.com.
}

Objective: Sclerosing lipogranuloma of the penis is a relatively rare disorder associated with injection of illicit foreign materials for penile augmentation. We aim to report the clinical presentation, diagnosis, treatment, and outcomes of patients with this condition, and to review the most relevant literature currently available.

Background: Injection of mineral oil into the subcutaneous tissues of the penis for augmentation has been practiced since ancient times. The potential for complications has long been known, and most doctors have abandoned the procedure. However, it is still practiced in some parts of the world. The complications may be devastating including death from embolism or sepsis. The affected area may not be restricted to the injection site, potentially involving the scrotal and suprapubic areas. Surgery with complete removal of the involved tissue followed by covering the denuded area with a graft or skin flap is the best therapeutic option.

Methods: The literature search involved keywords such as penis, augmentation, enlargement, sclerosing, lipogranuloma, penile injection, paraffinoma, and was obtained from computerized search of databases such as PubMed, Google Search and Scopus. Personal experience of the lead author (BS) is also described. We tried arbitrarily to limit our search to articles including $\geq 5$ patients pertaining to the subject of our review and, therefore, excluded single case reports. However, a single systematic search of PubMed and Scopus was also found and included.

Conclusions: The treatment of choice is radical excision of all the lesions followed by skin grafting. Bearing in mind that prospective, randomized, controlled studies are considered difficult to carry out, further work will continue apparently to be based on case series by individual surgeons. It is critical to advise patients to separate the myths from the facts and use preventive measures through awareness and education to best minimize the downsides of this problem.

Keywords: Penis; sclerosing; lipogranuloma; paraffinoma; augmentation; reconstruction

Submitted Dec 01, 2020. Accepted for publication Apr 23, 2021.

doi: $10.21037 /$ tau-21-228

View this article at: http://dx.doi.org/10.21037/tau-21-228

^ ORCID: João Felicio, 0000-0001-9124-7946; Francisco E. Martins, 0000-0002-5718-6964. 


\section{Introduction}

Since ancient times, the size of the phallus has been a source of anxiety to men having social and mental implications, including lack of self-confidence and self-esteem. A big sexual organ was viewed as a symbol of physical fitness, especially related to sexuality (1-4). Effort to enlarge the penis has been recorded through the ages and across cultures (5). Foreign materials such as liquid paraffin, mineral oils, and silicone have been used for more than 100 years to improve penile shaft contour and dimensions (6). The subcutaneous injections with hard and soft paraffin became a popular technique in the early $20^{\text {th }}$ century; nevertheless, the severe damaging consequences of such injections became widely known later $(7,8)$.

Reaction to the injection of these foreign substances tend to occur 1 to 2 years after the injection with the sclerosing chronic inflammation often leading to functional impairment (9). Skin gangrene, local migration, blindness, embolization, sepsis, and death have been reported $(10,11)$. Late sequelae, which can manifest several years later, include the development of foreign body granulomas, known as paraffinomas that are associated with massive tissue destruction (8).

The name sclerosing lipogranuloma of the penis was pioneered by Smetana and Bernhard in 1950 depicting subcutaneous inflammatory responses to endogenous broken-down lipids following tissue injury $(12,13)$. The abnormality has been termed after the injected substance (e.g., paraffinoma or vaselinoma), but it is also known as sclerotizing lipogranuloma or liponecrosis (7) (Table 1). Sclerosing lipogranuloma does not always progress following injection. Different reactions may also occur likely related to the chemical impure and unsterile nature of the injected substance in other areas of the body (14). Granick et al. stressed that the injection of impure, unsterile non-medically approved substances in significant quantities and in extensive areas are the critical deleterious factors behind this illegal, useless and unjustified procedure surrounded by dangerous risks to human health. For Bradley et al. the critical factor for the development of sclerosing lipogranuloma was the sensitivity of the patient's tissue (15). The practice of penile injection is still common in southeast Asia, Korea, Middle East, some Eastern European countries, and Indonesia (1,2,8,16-18) (Figure 1). We present the following article in accordance with the Narrative Review Reporting Checklist (available at http:// dx.doi.org/10.21037/tau-21-228) via a systematic search
Table 1 Various names of sclerosing inflammation after penile injection

\begin{tabular}{l}
\hline Various sclerosing names \\
\hline Penile paraffinoma \\
Penile siliconoma \\
Penile vaselinoma \\
Mineral oil granuloma of the penis \\
Liponecrosis of the penis \\
Penile oleogranuloma \\
Sclerosing lipogranuloma of the penis \\
Penile foreign body granuloma
\end{tabular}

of PubMed, Google Search and Scopus using keywords such as penis, augmentation, enlargement, sclerosing, lipogranuloma, penile injection, and paraffinoma. Personal experience of the lead author (BS) is also described.

\section{Historical background}

Genital size has been a source of anxiety for men throughout history. Many men sense a need to increase the size of their penis to improve self-confidence, or to satisfy their partners (4). Conversation about the penis is often deemed taboo and socially intolerable. In other eras, it was the theme of light-hearted chat and jokes (19).

In some primordial tribes, foreign body injection to enhance the penile contour was part of cultural tradition (5). The Dayak Borneo tribe had a ritual of glans piercing followed by insertion of foreign bodies into the resultant holes for increased erogenous stimulation. The Topinama tribesmen of Brazil have a tradition of encouraging poisonous snakes to bite their penis to make it bigger (20).

The use of mineral oil for genital augmentation in modern time was first performed by Robert Gersuny. He injected Vaseline to a boy who had undergone bilateral orchiectomy because of genital tuberculosis $(1,16,21,22)$. The apparent success of the procedure led him to use Vaseline as filling material for other soft tissue defects in other body organs such as breast, cheek, eyelids, muscle, and nose (23). Later, paraffin injections were also used to treat urinary incontinence (24). Problems with this type of procedure were reported as early as 1906 by Heidingsfield. Two patients underwent mineral oil injection for facial wrinkles, developing unpleasant nodules on the face 


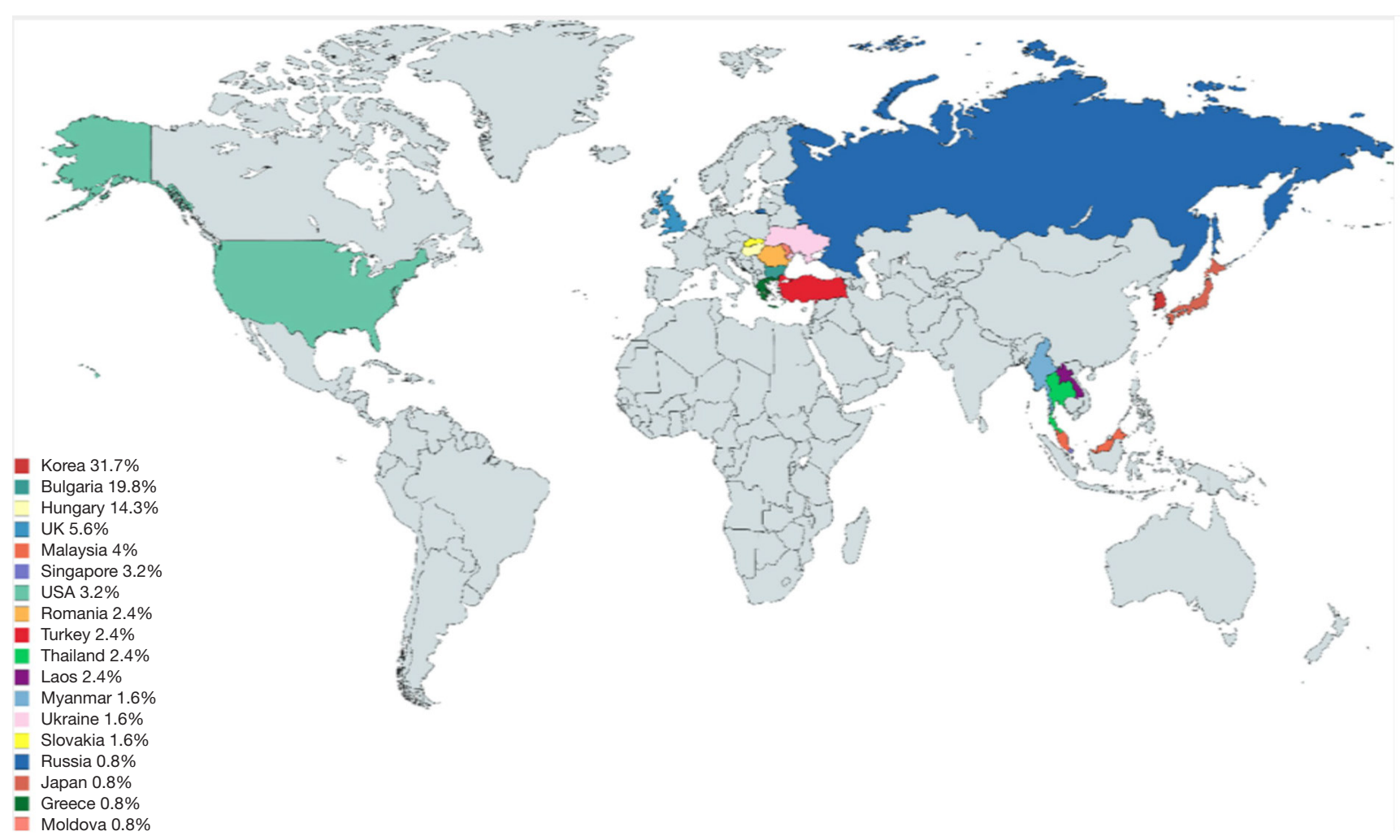

Figure 1 Geographical distribution of reported cases (reproduced with author's permission, Downey et al.).

Table 2 Types of injectable material $(5,24,26,27)$

Injectable material (medical substances)
Autologous fat
Polyacrylamide
Fluid silicone (polydimethylsiloxane)
Collagen
Hyaluronic acid
Injectable material (non-medical substances)
Mineral oil (incl. Coconut oil, Palm oil, olive oil)
Vaseline (liquified by warming)
Liquid paraffin
Metallic mercury
Petroleum jelly
Transmission fluid

$(21,22,25)$. Because of the complications, this practice was subsequently abandoned in many countries $(11,16)$. A list of the known injected materials is provided in Table 2. Most of these injected materials cannot be metabolized as the human body lacks the enzyme to break down exogenous lipids, causing a foreign body reaction (16,25). Delayed sequelae may include foreign body granulomas, and apparently an increased risk of penile cancer has also been described (24).

Life-threatening adverse reactions were also reported, including sepsis, pneumonitis and embolism associated with the inadvertent intravascular administration of the mineral oil (24).

In Indonesia, penile injections for phallic enlargement are commonly performed by the so called "traditional health practitioner" through a ritual combining penile and whole-body massage, acupuncture, natural oil, bamboo shafts of different sizes and spiritual power. Most likely, 

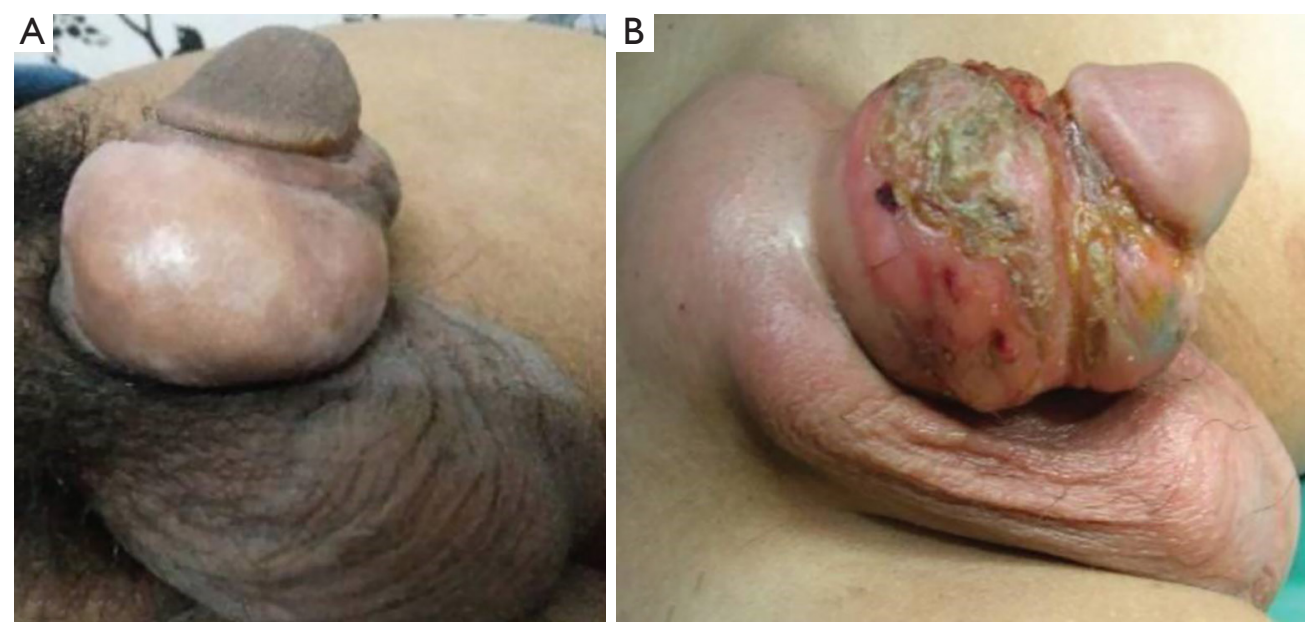

Figure 2 Sclerosing lipogranuloma of the penis. (A) Common appearance of sclerosing lipogranuloma of the penis (from author's personal archives). (B) Inflammation and ulceration after mineral oil injection. Notice the suprapubic fat involvement, but the scrotum is relatively free of defect (from author's personal archive).

the "acupuncture" consists of injection of one of different mineral oils, and the massage is performed to help divert the pain and to distribute the injected mineral oil evenly $(26,27)$. The author's institution receives many patients with penile sclerosing lipogranuloma following "treatment" by such traditional health practitioners.

\section{Clinical manifestation}

Clinical presentation varies according to the quantity of the injected material, composition, site of injection, depth, and time since injection (16). Symptoms occur in many patients almost instantly, particularly swelling, erythema and edema of the penile skin. A painless mass may be palpated along the penile shaft which will persist for years. Disastrous complications may be apparent from weeks to years after injection. Since many of the patients will try to conceal or deny any injections to the genitals, a thorough biochemical analysis of the lipid and material content after removal is mandatory to, at least, demonstrate its exogenous origin (28). Confronting the patient with proof of identified exogenous lipid may sometimes result in admission of its injection (28).

The injected materials and the tendency of the patient to massage the injected areas enable the injected materials to migrate to other areas of the external genitalia including regional lymph nodes leading to clinical confusion with cancer (13). Acquired phimosis can develop in uncircumcised patients, as the preputium can act as a storage for the injected materials (23). The migration is due to the large-volume, low-viscosity materials which do not allow encapsulation of the injected material (27). The migrated material can also fill the suprapubic area and the scrotum making reconstruction of the deformity more difficult, as the scrotum is an excellent source of skin graft to cover the defect after excision of the scarred area.

The painless mass will gradually become fibrotic, harder, occasionally painful and ulcerative (Figure 2), hence the term 'woody penis' (29). The skin becomes sensitive at the injection site, often with dark yellowish discoloration. This process may result in abscess formation, lymphangitis, and inguinal adenopathy (30). Penile deformity and painful erection may result from the hardened skin $(3,13)$. The glans and the cavernosal bodies are usually not involved, unlike the subcoronal sulcus that may be affected (30). Complaints also include difficult intercourse and coital pain for both the patient and the female partner $(3,31)$.

Most patients are unsatisfied with the result (24). Even in patients with no or minimal complications, discomfort and decreased erectile rigidity are commonly reported (9). MRI can be useful in delineating a deeper extension, inaccessible or difficult to palpation. It can also allow better characterization of involvement of the corpora cavernosa, corpus spongiosum and scrotal contents.

\section{Histological manifestation}

Histopathological examination of the excised specimen can confirm the presence and type of the injected exogenous 
Table 3 Classification of sclerosing lipogranuloma of the penis (as proposed by Soebhali)

\begin{tabular}{ll}
\hline Category & Content \\
\hline Category 1 & Minimal lesion, less than one-third of the penis, no suprapubic or scrotal involvement \\
Category 2 & Lesion in the shaft penis, more than one-third of the penis, no suprapubic or scrotal involvement \\
Category 3 & Lesion in the shaft penis, with suprapubic involvement, and half or less scrotal involvement category \\
Category 4 & Lesion in the penis, suprapubic and more than half of the scrotum \\
\hline
\end{tabular}
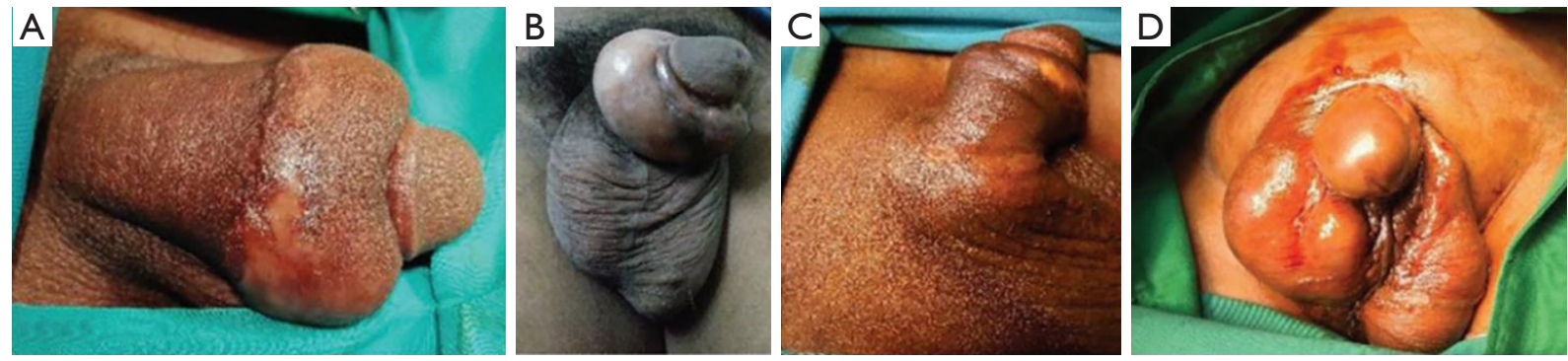

Figure 3 Classification of sclerosing lipogranuloma of the penis. (A) Category 1; (B) category 2; (C) category 3 ; (D) category 4 (see classification in text) (from author's personal archive).

material surrounded by an inflammatory reaction, and simultaneously excluding malignancy. In the initial phase, acute inflammatory cells along with abscesses and phlegmonous reaction can be observed in and around the vacuoles and marked thickening of the reticular dermis $(7,11,13)$. Anecdotally, injection of mineral oils has been associated with squamous cell carcinoma in another region of the body (32).

\section{Classification}

Currently, there is no widely accepted classification of sclerosing lipogranuloma. In 2012, Sejben proposed a classification according to local, locoregional and systemic forms (25). This classification also reflects the incidence of each category. In our institutions, we follow another classification proposed by the lead author (BS) as a guide for the management of this disorder. In many cases, the problem is localized in the penis, with or without scrotal and suprapubic fat involvement (25). The main aspect of this classification is the involvement of the surrounding area of injection, as described in Table 3 and shown in Figure 3.

\section{Treatment}

Although no standardized treatment protocols exist, it is universally accepted that surgical removal of the foreign material and granuloma, followed by appropriate skin grafting is needed even following a protracted latency period as reported by Eandi et al. in a patient seeking medical treatment 40 years after repeated injections (33). The key purpose of treatment is to restore penile function as a sexual organ with adequate cosmetic appearance (3). Many options have been proposed for the treatment of sclerosing lipogranuloma of the penis. A conservative approach using analgesia and antibiotics has been used to minimize the infectious complications (23). This non-curative treatment approach is also useful mostly for reassuring purposes in patients who are afraid of or reluctant to undergo surgery (34). No spontaneous regression of these granulomas has been reported (21).

Surgery is the best therapeutic option for this disease $(3,28,35)$. Surgery involves complex reconstructive procedures; it is time consuming and may require a staged approach involving bi-pedicled or bilateral scrotal flaps (17,24,36-39). Complete excision is critical to remove all the granuloma material, even extending to the suprapubic area, and involved regional adenopathy (28). This should be achieved to avoid recurrence with even worse scars or skin necrosis $(13,23)$ (Figure 4). If subcoronal sulcus is involved, the glans needs to be excised too to prevent a "hard band" around the glans.

In our centers, we prefer to perform surgery at least 6 

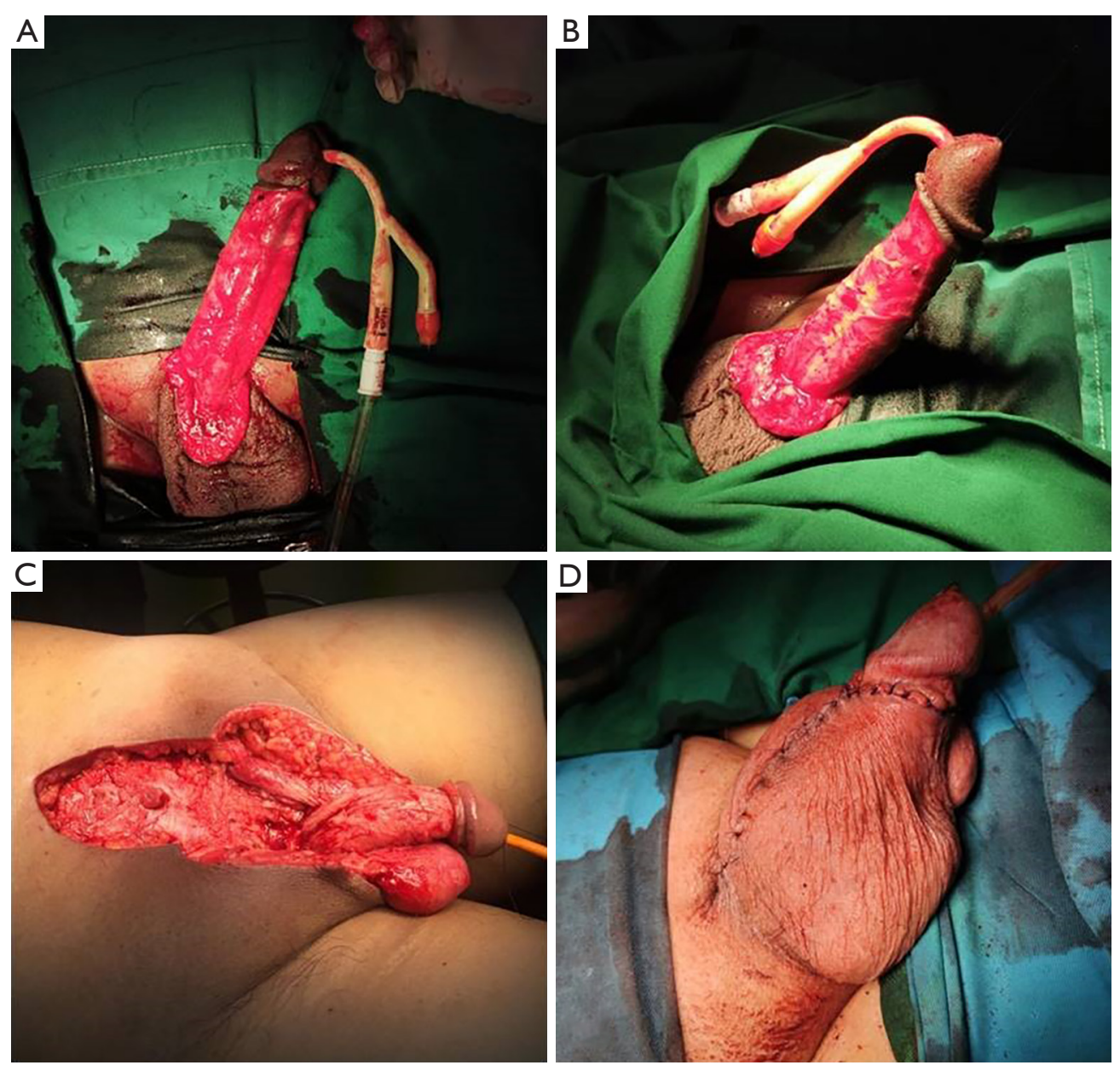

Figure 4 The first stage of Cecil's scrotal flap. (A,B) A circular incision was made followed by a longitudinal incision up to the suprapubic area (ventral and lateral view), then the penis was degloved; (C) further exploration showed the lipogranuloma at the suprapubic area being excised; (D) the scrotal skin was used to cover the penis (from author's personal archive).

months after injection. Local inflammatory and fibrotic reaction will take around 4-6 months to subside, making the surgical planes easier to identify after a varying period of antibiotic and non-steroidal anti-inflammatory coverage. Reconstruction of the defect(s) after complete excision varies, depending on the location and size of the defect. For small and isolated lesions (up to one third of the penis), primary closure or circumcision are usually sufficient (23). Wider defects must be closed with skin transfer. Split thickness skin graft (STSG), full thickness skin graft (FTSG), inner thigh flap, scrotal flap and Cecil's scrotal embedment of the penis are some of the techniques used $(9,18)$. For non-reconstructive surgeons, the Cecil's staged scrotal flap operation is a good choice for its relative simplicity (Figures 4,5). The bi-pedicled scrotal flap technique can still be performed even if more than half of the penile skin is involved $(17,35,37,38,40)$.

Although a relatively simple procedure, there are some key points to keep in mind to achieve a good surgical outcome: removal of all the lipogranuloma material, even involving the glans and suprapubic area. Another key aspect is the length of the scrotal incision, which must be at least the same as the penile length, otherwise risking shorten the penis. The dartos layer in the scrotal skin will allow the penis to "slide", giving the penis a "real skin" feel, unlike skin grafts, which will stick to the corporal bodies. Drainage of the scrotum and the suprapubic area is critical to avoid hematoma. A Foley urethral catheter and a compressive dressing are left in place for 3-4 days. In the lead author's experience (BS) of 356 patients treated from May 2008 to 

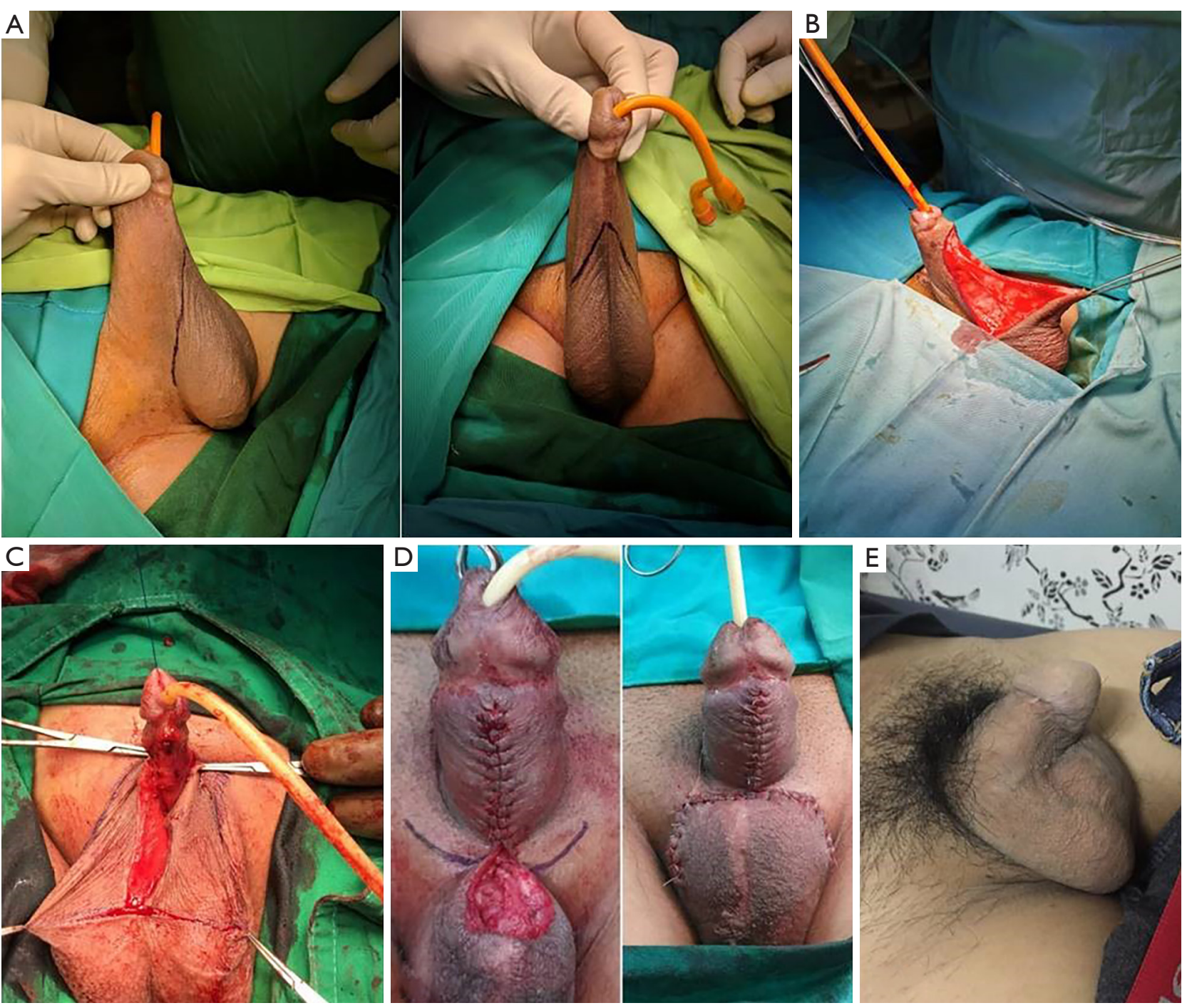

Figure 5 The second stage of Cecil's scrotal flap procedure. (A) the appearance of the scrotal-skin-covered penis 6 months after the first stage, and an inverted-U (or inverted V) incision was made on the ventral side; (B) the penis is then released from the scrotal skin; (C) thereafter, an inverted Y suture is made and a Penrose drain is placed in the scrotum to prevent hematoma; (D) closure of the skin incisions; (E) appearance of the penis 4 months after surgery (from author's personal archive).

December 2017, 21\% of the patients refused to undergo the second stage, as they were satisfied with the first stage. The disadvantages of the Cecil's staged scrotal flap technique are the ones inherent to all staged operations with associated psychological and economic impact (9). Hairy penis is also a 'relative' disadvantage (Figure 6). However, most patients refuse further surgery for a hairy penis. Penile shortening may be an additional concern, but this can be treated with a simple V-Y plasty for penile elongation.

\section{Literature evidence synthesis}

We could find only one systematic search of the English literature through PubMed and Scopus by Downey et al. that summarizes the currently available "relevant" literature on the subject, which is worth discussing in more detail due to its unique review and global nature (40). A total of 10 case series and 26 case reports were identified between 1956 and 2017, totaling 124 cases, with a mean age of 36.3 years (range, 17-71). Apparently concentrating its 


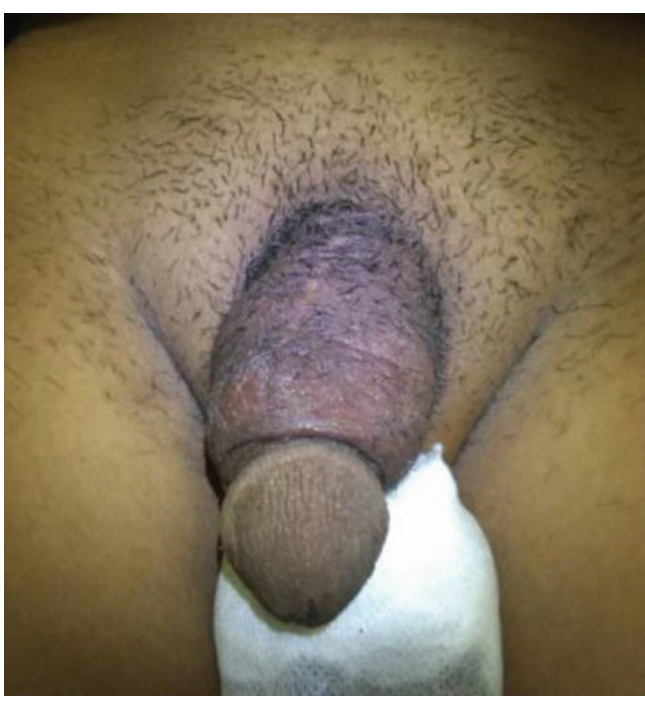

Figure 6 Hairy penis after second-stage surgery (from author's personal archive).

geographic distribution in eastern Europe and southeast Asia, the majority originated in Korea (31.7\%), Bulgaria (19.8\%), and Hungary (14.3\%) with a much lower incidence in southeast Asia (1.6\% to 3.2\%). Liquid paraffin was the most common injected material (80.2\%) followed by silicone and some mineral oils $(0.8-4.8 \%)$. The interval between injection and presentation averaged 24 months.

Clinical presentation included penile pain and swelling (30.2\%), ulceration/fistulae (15.4\%), deformity (11.4\%), phimosis or paraphimosis $(8.7 \%)$, skin necrosis $(4.7 \%)$ and voiding dysfunction (5.4\%). Potential life-threatening complications such as penile/penoscrotal gangrene and sepsis with palpable inguinal lymphadenopathy occurred in $4.7 \%$ of cases. There was one report of penile squamous cell carcinoma 35 years after mineral oil injection.

Both ultrasound scan (14.8\%) and magnetic resonance imaging $(14.3 \%)$ were the two mostly employed tools aiding in diagnosis and surgical planning. Management varied widely from surveillance and analgesic and antibiotic therapy $(8.7 \%$ and $5.6 \%$, respectively), and a 2 -stage surgical reconstruction involving extensive excision and debridement of the granulomatous mass, scrotal embedment followed by scrotal flap reconstruction 2-6 months later.

Histology was reported in 70 cases, the most common finding being giant cell infiltration and lipid vacuoles suggestive of lipogranuloma. Although not specifically mentioned, apparently, urinary, and sexual functions were preserved or recovered. Apparently, all these features are in line with the experience of the authors of this review.

\section{Conclusions}

Although generally uncommon, penile injection of exogenous non-medical materials, mostly performed by non-medical personnel, is a significant clinical entity. Although some decline has been observed, it remains prevalent in some parts of the world with disastrous medical and psychosocial complications. Chronic sclerosing inflammation will lead to hard nodules, cellulitis, skin ulceration, penile deformity, painful erection, and inability to perform sexual intercourse.

Although no standardized therapeutic protocol exists, surgery remains the mainstay of definitive treatment. Single-stage or multiple-stage reconstructions depend mainly on the severity of the problem and surgeon preference. Clearly, prevention of this practice through public health awareness and education campaigns in areas of high prevalence is paramount.

\section{Acknowledgments}

Funding: None.

\section{Footnote}

Provenance and Peer Review: This article was commissioned by the editorial office, Translational Andrology and Urology for the series "Controversies and Considerations of Penile Surgery". The article has undergone external peer review.

Reporting Checklist: The authors have completed the Narrative Review Reporting Checklist. Available at http:// dx.doi.org/10.21037/tau-21-228

Peer Review File: Available at http://dx.doi.org/10.21037/ tau-21-228

Conflicts of Interest: The authors have completed the ICMJE uniform disclosure form (available at http://dx.doi. org/10.21037/tau-21-228). The series "Controversies and Considerations of Penile Surgery" was commissioned by the editorial office without any funding or sponsorship. FM served as the unpaid Guest Editor of the series. The authors 
have no other conflicts of interest to declare.

Ethical Statement: The authors are accountable for all aspects of the work in ensuring that questions related to the accuracy or integrity of any part of the work are appropriately investigated and resolved.

Open Access Statement: This is an Open Access article distributed in accordance with the Creative Commons Attribution-NonCommercial-NoDerivs 4.0 International License (CC BY-NC-ND 4.0), which permits the noncommercial replication and distribution of the article with the strict proviso that no changes or edits are made and the original work is properly cited (including links to both the formal publication through the relevant DOI and the license). See: https://creativecommons.org/licenses/by-nc-nd/4.0/.

\section{References}

1. Pehlivanov G, Kavaklieva S, Kazandjieva J, et al. Foreignbody granuloma of the penis in sexually active individuals (penile paraffinoma). J Eur Acad Dermatol Venereol 2008;22:845-51.

2. Rosecker Á, Bordás N, Pajor L, et al. Hungarian "jailhouse rock": incidence and morbidity of vaseline self-injection of the penis. J Sex Med 2013;10:509-15.

3. Inn FX, Imran F-H, Ali MF, et al. Penile augmentation with resultant foreign material granuloma and sequalae. Malays J Med Sci 2012;19:81-83.

4. Vardi Y, Lowenstein L. Penile enlargement surgery-fact or illusion? Nat Clin Pract Urol 2005;2:114-5.

5. Kadouch JA, van Rozelaar L, Kanhai RJC, et al. Complications of penis or scrotum enlargement due to injections with permanent filling substances: Dermatol Surg 2012;38:1244-50.

6. Hohaus K, Bley B, Köstler E, et al. Mineral oil granuloma of the penis. J Eur Acad Dermatol Venereol 2003; $17: 585-7$.

7. Nyirády P, Kelemen Z, Kiss A, et al. Treatment and outcome of vaseline-induced sclerosing lipogranuloma of the penis. Urology 2008;71:1132-7.

8. Pónyai K, Marschalkó M, Hársing J, et al. Paraffinoma. JDDG J Dtsch Dermatol Ges 2010;8:686-8.

9. Lee T, Choi HR, Lee YT, et al. Paraffinoma of the penis. Yonsei Med J 1994;35:344-8.

10. Bajory Z, Mohos G, Rosecker Á, et al. Surgical solutions for the complications of the Vaseline self-injection of the penis. J Sex Med 2013;10:1170-7.
11. Cohen JL, Keoleian CM, Krull EA. Penile paraffinoma: self-injection with mineral oil. J Am Acad Dermatol 2002;47:S251-3.

12. Arthaud JB. Silicone-induced penile sclerosing lipogranuloma. J Urol 1973;110:210.

13. Steffens J, Kosharskyy B, Hiebl R, et al. Paraffinoma of the external genitalia after autoinjection of vaseline. Eur Urol 2000;38:778-81.

14. Granick MS, Solomon MP, Mosely LH, et al. Devastating granulomata of the lower extremities resulting from cosmetic injection of adulterated liquid silicone. Plast Reconstr Surg 1994;94:536-9.

15. Bradley RH Jr, Ehrgott WA. Paraffinoma of the penis: case report. J Urol 1951;65:453-9.

16. Foxton G, Vinciullo C, Tait CP, et al. Sclerosing lipogranuloma of the penis. Australas J Dermatol 2011;52:e12-4.

17. Fakin R, Zimmermann S, Jindarak S, et al. Reconstruction of penile shaft defects following silicone injection by bipedicled anterior scrotal flap. J Urol 2017;197:1166-70.

18. Soebhali B. Penile self-injections for girth augmentation: treatment of complications. In: Textbook of Male Genitourethral Reconstruction. Springer Nature Switzerland, 2020:83-794.

19. Dillon BE, Chama NB, Honig SC. Penile size and penile enlargement surgery: a review. Int J Impot Res 2008;20:519-29.

20. Wylie KR, Eardley I. Penile size and the 'small penis syndrome' BJU Int 2007;99:1449-55.

21. Bayraktar N, Başar İ. Penile paraffinoma. Case Rep Urol 2012;2012:202840.

22. Santos P, Chaveiro A, Nunes G, et al. Penile paraffinoma. J Eur Acad Dermatol Venereol 2003;17:583-4.

23. Rosenberg E, Romanowsky I, Asali M, et al. Three cases of penile paraffinoma: a conservative approach. Urology 2007;70:372.e9-e10.

24. Turner B, Goldstraw E, Pati J. Penile paraffinoma. Int J Urol Nurs 2013;7:53-6.

25. Sejben I, Rácz A, Svébis M, et al. Petroleum jellyinduced penile paraffinoma with inguinal lymphadenitis mimicking incarcerated inguinal hernia. Can Urol Assoc J 2012;6:E137.

26. Casavantes L, Lemperle G, Morales P. Penile girth enhancement with polymethylmethacrylate-based soft tissue fillers. J Sex Med 2016;13:1414-22.

27. Silberstein J, Downs T, Goldstein I. Penile injection with silicone: case report and review of the literature. J Sex Med 2008;5:2231-7. 
28. Arduino LJ. Sclerosing Lipogranuloma of Male Genitalia. J Urol 1959;82:155-61.

29. Manny T, Pettus J, Hemal A, et al. Penile sclerosing lipogranulomas and disfigurement from use of "1Super Extenze" among Laotian Immigrants. J Sex Med 2011;8:3505-10.

30. Zalar Jr JA, Knode RE, Mir JA. Lipogranuloma of the penis. J Urol 1969;102:75-7.

31. Shaeer O, Shaeer K. Delayed complications of gel injection for penile girth augmentation. J Sex Med 2009;6:2072-8.

32. Ko CJ, Sarantopoulos GP, Bhuta S, et al. Scalp paraffinoma underlying squamous cell carcinoma. Arch Pathol Lab Med 2004;128:1171-2.

33. Eandi JA, Yao AP, Javidan J. Penile paraffinoma: the delayed presentation. Int Urol Nephrol 2007;39:553-5.

34. Choudhury N, Frame JD, Lewi HJE. Penile paraffinoma and a novel treatment. BJU Int 2003;92:e14.

Cite this article as: Soebhali B, Felicio J, Oliveira P, Martins FE. Sclerosing lipogranuloma of the penis: a narrative review of complications and treatment. Transl Androl Urol 2021;10(6):2705-2714. doi: 10.21037/tau-21-228
35. Shin YS, Zhao C, Park JK. New reconstructive surgery for penile paraffinoma to prevent necrosis of ventral penile skin. Urology 2013;81:437-441.

36. Bjurlin MA, Carlsen J, Grevious M, et al. Mineral oilinduced sclerosing lipogranuloma of the penis. J Clin Aesthet Dermatol 2010;3:41-4.

37. Jung G, Park SJ, Seo J, et al. A novel penoplasty technique for severe paraffinoma: modified bilateral scrotal flaps. J Urol 2012;187:e40.

38. Kim SW, Yoon BI, Ha US, et al. Treatment of paraffininduced lipogranuloma of the penis by bipedicled scrotal flap with Y-V incision. Ann Plast Surg 2014;73:692-5.

39. Salauddin SA, Ghazali H. Surgical techniques for correction of penile paraffinoma. Malays J Med Sci 2019;26:137-42.

40. Downey AP, Osman NI, Mangera A, et al. Penile paraffinoma. Eur Urol Focus 2019;5:894-8. 